\title{
INSERÇÃO PROFISSIONAL DE ASSISTENTES SOCIAIS NOS CUIDADOS PALIATIVOS EM PORTUGAL
}

\author{
THE PROFESSIONAL INTEGRATION OF SOCIAL WORKERS IN PALLIATIVE \\ CARE SERVICES IN PORTUGAL
}

\author{
Ana Rita Silva ${ }^{1}$ \\ Sónia Guadalupe $e^{2}$
}

\section{RESUMO}

Pela centralidade que o Serviço Social assume na defesa e garantia da cidadania e dos direitos humanos no contexto dos cuidados de saúde, o presente estudo pretende analisar a inserção dos profissionais de Serviço Social em cuidados paliativos em Portugal. Os resultados do estudo, com base num inquérito a 17 assistentes sociais que trabalham em cuidados paliativos, mostram-nos que os assistentes sociais estão inseridos em 86,4\% das unidades/equipas existentes a nível nacional, sendo estas maioritariamente de natureza pública (75\%). A maioria dos profissionais inquiridos tem formação pós-graduada $(64,7 \%)$, formação específica na área $(82,4 \%)$ e apoio institucional para formação continuada. As condições de trabalho atuais tiveram uma avaliação tendencialmente desfavorável por parte da amostra. $\mathrm{O}$ artigo pretende contribuir para a reflexão sobre o Serviço Social no exigente contexto dos cuidados paliativos e sobre o direito dos cidadãos a cuidados de saúde holísticos e de qualidade em Portugal.

PALAVRAS-CHAVE: Cuidados Paliativos. Serviço Social. Assistente Social. Cuidados de saúde

\begin{abstract}
By the relevance that social work assumes in the defense of citizenship and human rights in the context of health care, this study aims to examine the integration of social workers in palliative care services in Portugal. The results of the study, based on a survey with 17 social workers working in palliative care, show us that social workers are included in $86.4 \%$ of the services that exist at national level, which are mostly public (75\%). Most respondents have postgraduate studies (64.7\%), specific professional training in the area (82.4\%) and institutional support for continued training. The current work conditions had a tendentiously unfavorable assessment by the sample. The article aims to contribute for the reflection about social work in the demanding context of palliative care and about the right of citizens to an holistic and quality health care in Portugal.
\end{abstract}

KEYWORDS: Palliative Care. Social Work. Social Worker. Health Care.

\footnotetext{
${ }^{1}$ Assistente Social; Licenciada em Serviço Social pela Universidade dos Açores (Portugal); Mestre em Serviço Social pelo Instituto Superior Miguel Torga (Portugal). E-mail: anarita_ss17@hotmail.com. 2 Assistente Social; Professora Auxiliar no Instituto Superior Miguel Torga (Portugal); Investigadora integrada do CEPESE, Centro de Estudos da População, Economia e Sociedade (Portugal); Investigadora associada do CIES-IUL, Centro de Investigação e Estudos de Sociologia do Instituto Universitário de Lisboa (Portugal); Licenciada em Serviço Social; Mestre em Família e Sistemas Sociais; Doutorada em Saúde Mental; Doutoranda em Serviço Social. E-mail: guadalupe@ismt.pt. Telefone: 00351239488030.
} 


\section{INTRODUÇÃO}

\section{Evolução dos cuidados paliativos: o caso português}

Ao longo dos tempos, a forma como as pessoas encaram a morte e o sofrimento foi-se modificando. "Morrer faz parte da vida, porém ao longo da História a sociedade parece ter distorcido essa realidade" (BRAGA; QUEIROZ, 2013, p. 415), ou levado a encará-la, individualmente e em sociedade, de forma distinta através dos tempos e das culturas, assim como as formas de cuidar do doente no termo da vida.

Desde o século XIX que diversos grupos, maioritariamente religiosos, se dedicavam aos cuidados dos moribundos e mais carenciados, "numa tentativa meritória de ultrapassar alguma negligência de que estes eram alvo pela própria sociedade" (NETO, 2006, p. 18). O objetivo destes cuidados em fim de vida seria o de oferecer uma boa morte (FLORIANI; SCHARAMM, 2008, p. 2124). Este modelo de "morrer bem" vai em contraposição com o uso de técnicas para o prolongamento da vida (MENEZES, 2003, p. 129), foco da Medicina ocidental. Parece, assim, interromper-se uma tendência para a negação da morte, no mundo ocidental moderno, muito presente nos profissionais de saúde (COMBINATO; QUEIROZ, 2011, p. 3893), sobretudo treinados para a cura, representando a morte uma falha e um sentimento de frustração por parte dos mesmos. Neto (2009, p. 31) refere mesmo que "morrer só é corolário de uma medicina que entronizou a cura e que acha que as pessoas que não se curam são insucessos, afastandose delas”. Esta perceção de desresponsabilização pelos cuidados de saúde que eram prestados aos doentes crónicos e incuráveis leva ao surgimento do movimento moderno dos cuidados paliativos, iniciado em Inglaterra na década de 60 do século XX, tendo-se depois alargando à América do Norte e, mais recentemente (nos últimos quarenta anos do século XX), aos restantes países da Europa (FLORIANI; SCHARAMN, 2010; NETO, 2006; REITH; PAYNE, 2009). A sua origem remonta ao St. Christopher Hospice por Dame Cicley Saunders em Londres, sendo, por isso, denominado de movimento hospice que "representa o fruto mais significativo deste modo de situar a pessoa em fase terminal e reflecte a necessidade de acompanhamento dos doentes terminais" (MOREIRA, 2001, p. 44).

Contudo, a introdução dos cuidados paliativos em Portugal foi muito mais tardia do que se verifica noutros países europeus, tratando-se de "uma actividade recente, tendo as primeiras iniciativas surgido apenas no início dos anos 90 do século passado" 
(MARQUES et al., 2009, p. 32). Segundo Marques et al. (2009) esta visão paliativa perante a doença incurável, muito próxima da que nos deparamos nos nossos dias, é encontrada em textos médicos portugueses do século XVI, o que contrasta com a tardia implementação dos cuidados paliativos verificada em Portugal.

Segundo dados do Eurostat (2013, p.73-75), constatamos que a evolução demográfica recente da União Europeia mostra um aumento da esperança média de vida, tornando a estrutura etária mais envelhecida, no caso de Portugal a média situavase em 2012 nos 80 anos (sexo masculino: 76,9 anos; sexo feminino: 82,8 anos). No entanto e em relação à média dos anos de vida saudável à nascença, Portugal apresenta uma média de 60.7 anos para o sexo masculino e 58.7 anos para o sexo feminino, ficando abaixo, em média, de 1 a 4 anos relativamente à média registada para a União Europeia e de 11 a 12 anos abaixo do país que regista a média mais elevada, a Suécia (EUROSTAT, 2013).

Assim, apesar do progresso social, após a revolução industrial, ter conduzido "a mudanças significativas no panorama das doenças e das condições de vida das populações" (MOREIRA, 2001, p. 33), registou-se um aumento significativo na “população vulnerável às doenças crónicas e às degenerativas associadas à velhice” bem como às polipatologias ou comorbilidades (CABRAL et al., 2002, p. 30). Com isso, regista-se, de igual forma, o aumento do número de doentes em situação terminal, tendo em conta esta crescente longevidade e o aumento das doenças crónicas e progressivas (ANCP, 2009, p. 14).

Em 2011, em Portugal 30,6\% da população doente autodeclara-se com doença prolongada, sendo a média da União Europeia de 31,2\% (EUROSTAT, 2013, p. 74). Segundo a UMCCI (2010a) estimavam que pelo

[...] aumento progressivo do número de população idosa [...], 60\% a $75 \%$ dos indivíduos 'morrerá depois de um período de doença crónica progressiva, que poderá incluir uma situação de doença avançada ou terminal. [Neste sentido,] é necessário responder e salvaguardar as atuais e futuras necessidades dos cuidados de saúde da população portuguesa' (ibid., p. 9).

Outros fatores, para além da evolução dos dados demográficos e epidemiológicos, exigem, de facto, um desenvolvimento urgente de cuidados paliativos organizados, atendendo, nomeadamente a "redução do número de famílias alargadas, o aumento da industrialização e a entrada da mulher no mercado laboral" (CLARK, 2002; LYNN, 2000 apud NETO, 2006, p. 18) que colocam inúmeros desafios sociais, Serv. Soc. \& Saúde, Campinas, SP v.14, n.1(19), p. 57-90, jan./jun. 2015 ISSN 1676-6806 
sobretudo face às crescentes dificuldades na conciliação da vida familiar e do cuidar informalmente com a vida profissional, quer às famílias quer ao próprio sistema de saúde, no tipo de apoio que é prestado a estes doentes.

Face a tais desafios, a OMS assinala a necessidade de ampliar a definição de cuidados paliativos publicada em 1990 passando a focalizar não só o doente como também a família, em 2002 redefine-a, passando a constar como a "abordagem que visa melhorar a qualidade de vida dos doentes - e suas famílias - que enfrentam problemas decorrentes de uma doença incurável e/ou grave e com prognóstico limitado, através da prevenção e alívio do sofrimento, da preparação e gestão do fim de vida e do apoio no luto, com recurso à identificação precoce e tratamento rigoroso dos problemas não só físicos mas também psicossociais e espirituais" (ANCP, 2006, p. 2).

Ao longo dos últimos anos tem-se vindo a registar "um alargamento deste conceito de cuidados paliativos" (PEREIRA, 2011, p. 29), tendo sido adotadas e ampliadas definições por parte de diversas entidades e documentos, como são exemplo o Programa Nacional de Cuidados Paliativos Direção Geral da Saúde (2005), a Lei de Bases de Cuidados Paliativos e a Associação Portuguesa de Cuidados Paliativos. Este alargamento tem originado "um aprofundamento da reflexão em torno do seu verdadeiro significado" (PEREIRA, 2011, p. 30). No entanto, Marrero e Pereira (2013, p. 1) alertam para que, apesar destas definições emanadas por diversas associações, é necessário esclarecerem-se alguns aspetos para se obter um maior consenso em torno de uma definição global para os cuidados paliativos, sendo que várias iniciativas têm sido realizadas nesse sentido, tendo em conta que um consenso conceitual permitiria comparações nacionais e transculturais mais eficazes dos sistemas de cuidados de saúde, contribuindo para uma melhoria dos cuidados.

Os cuidados paliativos devem ser prestados a doentes que não têm perspectiva de tratamento curativo, apresentando um "prognóstico de vida limitado" (PNCP, 2004, p. 19). Com isto não se deve entender que os mesmos são remetidos para uma ideia de "fim de linha", salientando Neto (2010, p. 16) que tais cuidados se destinam a todos os doentes que deles necessitam, independentemente da sua idade e patologias, sendo prestados ao longo de semanas, meses e até mesmo anos. Na mesma perspectiva se coloca a APCP, afirmando que "não são só os doentes incuráveis e avançados que poderão receber estes cuidados. A existência de uma doença grave e debilitante, ainda que incurável, pode determinar elevadas necessidades de saúde pelo sofrimento Serv. Soc. \& Saúde, Campinas, SP v. 14, n. 1 (19), p. 57-90, jan./jun. 2015 ISSN 1676-6806 
associado e, dessa forma, justificar a intervenção de cuidados paliativos, aqui numa perspectiva de suporte e não de fim de vida" (ANCP, 2006, p. 4). Dever-se-á, em primeira instância, reconhecer quem são os doentes que carecem destes cuidados para que a resposta prestada seja eficaz.

Em Portugal a prestação destes cuidados é assumida pelos estabelecimentos do Serviço Nacional de Saúde (SNS), podendo ser igualmente assegurados por entidades do setor solidário (terceiro sector) ou por instituições privadas, quando não assegurada resposta pública, de acordo com o estabelecido na Lei de Bases dos Cuidados Paliativos. Estes cuidados de saúde podem ser prestados em regime de internamento, de ambulatório ou domiciliário.

\section{O Serviço Social nos Cuidados Paliativos}

Nas décadas de 60 e 70 do século XX, Erich Lindemann, Cicely Saunders, Elizabeth Kubler-Ross e Colin Murray Parkes inspiraram o desenvolvimento do pensamento no modo como lidar com as consequências psicológicas, sociais e espirituais da morte. A estes quatro pioneiros se deve a introdução do Serviço Social nos cuidados paliativos. Reith e Payne (2009, p. 9 e 15) acrescentam que os assistentes sociais foram envolvidos desde o início no desenvolvimento destes cuidados. Saunders (1990 apud HOLLOWAY; TAPLIN, 2013) refere mesmo que (no contexto inglês) trabalhar com pessoas que se confrontam com a morte, bem como com as pessoas enlutadas, constitui uma das especialidades mais antigas no Serviço Social, tendo sido o assistente social considerado, desde o início, como um membro valioso da equipa multidisciplinar.

Em qualquer momento da sua vida profissional, o assistente social depara-se com questões de fim de vida. Mesmo que não trabalhem diretamente em cuidados paliativos, "estes profissionais podem ser chamados a ajudar todo o tipo de pessoas com questões de luto" (PAYNE, 2012, p. 117), assim como para intervir face ao impacte social de uma morte numa família.

Quando falamos em algum tipo de doença prolongada ou com poucas ou nenhumas perspectivas de cura, "tanto a pessoa doente quanto seus familiares enfrentam diversas dificuldades, as quais incluem desde situações de medo, ansiedade, dúvidas, até longos e dolorosos processos de tratamentos. Diferentes profissionais podem atuar no 
sentido de amenizar estas e outras dificuldades que possam surgir, entre os quais estão o médico, o enfermeiro e o assistente social” (SIMÃO et al., 2010, p. 353).

Simão et al. (2010, p. 353) sublinham que "os cuidados paliativos não prolongam a vida, nem tampouco aceleram a morte. $\mathrm{Na}$ verdade, eles são implementados para atender, de forma mais humanizada possível, ao paciente e à sua família”. Tudo isto implica uma mudança nos quadros de referência e nas prioridades de ação dos profissionais de saúde (MARTINS; ROMÃO, 2012). O processo de tratamento de um doente que se encontra a receber cuidados paliativos centra-se sobretudo

[...] na atenção da prática clínica aos factores que impeçam o doente de ter uma boa qualidade de vida e nas preocupações com as necessidades emocionais, psicológicas, sociais e espirituais, em conjunto com cuidados médicos e de enfermagem e de uma reabilitação eficaz em termos de uma condição física e adaptação psicológica e social. A integração de todos estes elementos de apoio facilita a continuidade de uma vida ativa de boa qualidade (PAYNE, 2012, p. 112).

Esta integração implica uma conceção holística da pessoa e dos cuidados.

Os assistentes sociais são formados em ciências sociais e não no conhecimento biomédico (PAYNE, 2007), trazendo dimensões distintas das outras profissões das equipas de saúde para o domínio dos cuidados, sendo que o foco de intervenção em cuidados paliativos, não seja orientado para a cura da doença (MARTINS; ROMÃO, 2012), traz-nos a distinção entre curar e cuidar, sendo que Martins (2010), no estudo que realizou, realça que o cuidar requer uma compreensão interpessoal baseada numa metodologia de escuta, abertura e negociação dos vários procedimentos de cuidados, não esquecendo as necessidades (mais subjetivas e pessoais).

A exigência acrescida do Serviço Social neste contexto de cuidados é, assim, caracterizado por exigências diversas entre gerir os aspetos práticos e os sentimentos, estando ao lado das pessoas enquanto estas passam por mudanças provocadas pelo processo de morrer (PAYNE, 2007, p. 69). Loyd (1997), no seu estudo, chegou à conclusão que os assistentes sociais têm, de facto, uma abordagem integral e as competências necessárias para incorporar tanto a dimensão individual como social da morte ou do processo de morrer. Na mesma linha, Simão et al. (2010, p. 361-362) e Palacio et al. (2008, p. 126) referem que apesar de a formação académica ser escassa e não oferecer todas as condições necessárias para a intervenção junto a pacientes terminais e suas famílias, este profissional detém outras competências que vai desenvolvendo 
ao longo da sua formação e vida profissional, podendo contribuir para humanizar os serviços e melhorar a qualidade de vida dos mesmos, dado possuir um saber que é imprescindível na atenção ao paciente e à sua família: a capacidade de escutar e de leitura da realidade social envolvente.

Desta forma, segundo Ramos (2009), o Serviço Social detém uma intervenção especializada, sendo que a mesma pode ser realizada em diversos contextos: em internamento/interconsulta (consultoria a profissionais), em consulta externa e em monotorização telefónica, de igual forma, fazendo uma articulação com as estruturas da comunidade; efetuando visitas domiciliárias (avaliação social domiciliária) e realizando consultas de luto.

Vanzini (2010, p. 186) afirma que os doentes, quando confrontados com a doença terminal, apresentam determinadas necessidades, que podem ser originadas tanto por fatores externos como internos à própria família. Em relação aos primeiros destaca os económicos (diminuição do rendimento), laborais (perda do trabalho ou dificuldade em mantê-lo pelos tratamentos/cuidados a que está sujeito) e sociais (deterioração, rejeição ou perda das redes de apoio por diversos motivos, desconhecimento acerca de direitos e de recursos sociais ou institucionais). No que toca aos fatores internos podemos referir todo o conjunto de impactes psicossociais na família, como as dificuldades em lidar com dimensões emocionais, como a ansiedade, depressão, medo, impotência, etc, assim como as necessárias adaptações conjunturais e estruturais que a situação exige. As necessidades sociais estão, desta forma, condicionadas por múltiplos fatores e são determinantes, em alguns casos, na hora de estabelecerem prioridades. Sendo que o "desafio de viver uma doença na família é tanto maior quanto mais inesperadamente surgir, quanto maior gravidade apresentar na sua evolução e quanto maior grau de incapacidade trouxer ao indivíduo" (GUADALUPE, 2012, p. 185).

$\mathrm{O}$ assistente social, perante o doente terminal, situa-se, assim, numa posição estratégica entre aquilo que o doente é e foi na sua vida e a situação em que o doente se encontra, na sua fase mais dependente, geralmente acamado, passivo e por vezes com dificuldade do seu projeto de vida. Por isso, o trabalho desenvolvido junto desses doentes deva ser efetuado o mais precocemente possível, sob pena de não se conseguir ir ao encontro das suas necessidades (RAMOS, 2009). 
$\mathrm{Na}$ área da saúde, os assistentes sociais, de um modo geral, exercem as suas funções

[...] no âmbito do acolhimento dos doentes e suas famílias, do apoio assistencial (económico e material), da informação sobre direitos e recursos sociais, do aconselhamento e suporte emocional na gestão da doença, da preparação da alta social e a coordenação e mobilização de recursos sociais (BRANCO, 2009, p. 80).

De um modo mais detalhado diversos autores apresentam um processo faseado de intervenção na prática profissional em cuidados paliativos, não devendo entender-se as fases como autónomas e independentes, mas como interligadas entre si.

As fases destacadas passam pelo acolhimento, acompanhamento e encaminhamento (CULLEN, CHADDOCK; HEARN, 2013; MATIAS, 2003; OLAIZOLA, 2006; REITH; PAYNE, 2009; VANZINI, 2010). No que toca à fase de acolhimento, o profissional deve acolher o doente e família transmitindo-lhes informações acerca do internamento; deve elaborar um diagnóstico social que integre a sua situação contextualizada, estabelecer os fatores de risco, assim como as prioridades de intervenção; estabelecer objetivos e traçar um plano de intervenção. É nesta fase que o assistente social tem oportunidade de ouvir as perceções e representações que o doente e família construíram acerca da doença e dos cuidados. Esta é uma fase com uma carga emocional exigente tanto para os profissionais, que desejam conseguir responder às dúvidas e preocupações expostas, bem como para o doente e família, que estão perante inúmeros desafios. Na fase de acompanhamento são transmitidas (em conjunto com os restantes profissionais) as informações inerentes à doença, como a natureza da mesma, tipos e sequência dos tratamentos, rotinas hospitalares; apoio na perceção e consequente adaptação do doente e família acerca de como será a sua vida e como reorganizá-la; orientar e acompanhar o doente e família no acesso direitos, recursos e apoios a que podem aceder tendo em conta as necessidades identificadas. Deve, ainda nesta fase inicial, proceder-se à identificação da rede de suporte social do doente, não bastando sinalizar apenas a sua existência, mas sim verificar se a mesma apresenta características capazes de proporcionar um suporte informal efetivo. Quando identificamos uma rede informal de suporte,

[...] é, com frequência no âmbito do sistema familiar que emergem os que protagonizam a relação de suporte mais continuado e também a relação com os serviços. Essa rede terá, muitas vezes de ser mobilizada e apoiada para que possa apoiar. Quando se verifica uma situação em que não existe uma rede de suporte social informal, há 
que intervir no sentido de criá-la, nomeadamente através de redes secundárias formais (GUADALUPE, 2012, p. 211).

Em relação à fase de encaminhamento, devem ser identificadas as principais dificuldades, bem como os desejos e preferências do doente (ou família) (CULLEN, CHADDOCK; HEARN, 2013; MATIAS, 2003; OLAIZOLA, 2006; REITH; PAYNE, 2009; VANZINI, 2010). Uma vez que a rede já foi identificada na fase diagnóstica, faz, de igual forma, parte da prática profissional do Serviço Social facilitar o acesso a direitos, bens e serviços, fazendo uma articulação com as respostas da comunidade para a adequada continuidade dos cuidados. Esta fase não deve ser entendida como a última, uma vez que mesmo depois da saída do utente da unidade o profissional deve manter contacto com os profissionais que continuam o seguimento bem como com o doente, por forma a controlarem a resposta (CULLEN, CHADDOCK; HEARN, 2013; MATIAS, 2003; OLAIZOLA, 2006; REITH; PAYNE, 2009; VANZINI, 2010).

O assistente social intervém, também, na preparação para o luto, que deve ser iniciada quando há conhecimento do prognóstico da doença e da sua irreversibilidade, dando continuidade à mesma ao longo de toda esta fase, uma vez que o doente e a sua família vão sendo alvo de perdas sucessivas que têm de ser bem geridas (RAMOS, 2009).

Pela cultura ocidental voltada para os fortes laços afetivos para com os familiares e pessoas mais próximas (PORTUGAL, 2011), a sociedade tem dificuldade em enfrentar a perda, o que acaba por ocasionar problemas na reestruturação da vida (LUZ; GOULART; BENINCÁ, 2007). Bruce e Schultz (2001 apud PAYNE, 2012) sugerem três itens que consideram indispensáveis no apoio prestado às pessoas na perda: "ajudar as pessoas a voltar a ganhar o controlo de situações sociais e das suas vidas; ajudar as pessoas a preservar a sua identidade pessoal e honrar a importância da perda que estão a sofrer ou que é eminente" (ibid., p. 124).

Schroepfer e Noh (2010), num estudo realizado com 100 doentes terminais concluíram que para 85 destes doentes a antecipação de um suporte social, desempenhava um papel muito importante no processo de morte. A maioria dos entrevistados, na discussão do apoio que se encontravam a receber, demonstrava no seu discurso a expectativa da continuidade do apoio ou até mesmo de um apoio adicional para a sua família. 
Ramos (2009) realça que este apoio é muito importante por forma a se evitar o luto patológico. A profissional chama ainda a atenção para o facto de o apoio no luto não cessar logo após a morte do doente. O assistente social, sempre que necessário dará apoio após a morte do falecido, de modo a diminuir as desvantagens sociais instaladas pelo falecimento, sendo importante que as pessoas se sintam parte de uma comunidade que os apoia (ASTUDILLO; MENDINUETA; CASADO, 2007; RAMOS, 2009).

Em todo o processo de intervenção nos cuidados paliativos realça-se o enfoque da comunicação e do suporte psicoemocional proporcionado ao doente e família. No entanto, Kovács (2004) afirma a existência de uma Medicina autoritária, onde a escuta aos pacientes e famílias é secundarizada. Os autores colocam esta comunicação em diferentes níveis, ou seja, a intervenção do profissional em facilitar a comunicação entre os membros da família e entre estes e a restante equipa de trabalho; em comunicar a verdade e a esperança e em comunicar as más notícias (PAYNE, 2009; RAMOS, 2009; REITH; PAYNE, 2012). Num estudo realizado com 303 profissionais da área da saúde, Araújo e Silva (2012) constataram que todos os profissionais evidenciaram o valor imenso que há na comunicação interpessoal no contexto de fim de vida. No entanto, estes profissionais revelam que há um escasso conhecimento de estratégias de comunicação no atendimento à dimensão emocional dos pacientes em cuidados paliativos.

Em Portugal, a prática profissional do Serviço Social no contexto dos cuidados paliativos é orientada e atualizada por vários guias profissionais; a nível nacional temos o Manual de Boas Práticas para os Assistentes Sociais da Saúde na Rede Nacional de Cuidados Continuados Integrados (DGS, 2006) que também focaliza o desempenho das funções do assistente social nas equipas intra-hospitalares de suporte em cuidados paliativos. A nível internacional temos, por exemplo, o The route to success in end of life care-achieving quality for social work do National End of Life Care Programme The college of Social Work (Inglaterra) e o NASW Standards for Palliative \& End of life Care, da National Association of Social Work (Estados Unidos da América).

Com estes e outros instrumentos, verifica-se geralmente uma adequação da prática profissional do assistente social neste campo de intervenção, "os valores e as perspectivas do trabalho social são particularmente bem alinhados com os dos cuidados paliativos, que é acima de tudo holística e centrada na pessoa" (CULLEN, CHADDOCK; HEARN, 2013, p. 2). A importância da intervenção do Serviço Social Serv. Soc. \& Saúde, Campinas, SP v. 14, n. 1 (19), p. 57-90, jan./jun. 2015 ISSN 1676-6806 
nos cuidados paliativos é fulcral, sendo também fundamental uma aposta na produção de conhecimento e de reflexão que sustente o desenvolvimento da prática profissional neste contexto específico.

\section{Objetivos}

Os amplos desafios colocados pela evolução demográfica e epidemiológica aliados às recentes transformações no sistema de saúde e nas políticas sociais, cada vez mais seletivas e restritivas, geraram um interesse acrescentado sobre a inserção profissional e as condições de trabalho do(a)s assistentes sociais, a partir da sua própria perspetiva, como profissionais da "linha da frente", especialmente no contexto de crise financeira, económica e social que Portugal e a Europa atravessam atualmente. Conscientes da pertinência que há no aprofundamento dos cuidados paliativos como área de intervenção do Serviço Social, procurámos analisar e compreender de que forma o(a)s assistentes sociais se encontram inseridos nesta área da saúde no contexto português, e como percebem e caracterizam as suas condições de trabalho.

O presente artigo apresenta parte dos resultados do estudo, caracterizando: o percurso formativo dos assistentes sociais (formação de base e pós-graduada); o tempo de exercício profissional; a evolução da unidade/equipa; a constituição da equipa de trabalho; a formação profissional da equipa e apoio à formação; a estabilidade da equipa; e as condições de trabalho percebidas na unidade.

\section{MATERIAL E MÉTODOS}

\section{Participantes}

Inquirimos, entre os meses de janeiro e maio de 2014, 17 profissionais, de um total de 38 instituições que contavam com a intervenção deste grupo profissional. A nível nacional foram identificadas 44 instituições ${ }^{3}$.

\footnotetext{
${ }^{3}$ Já após este levantamento, em outubro de 2014 é criada uma nova equipa comunitária de suporte em cuidados paliativos.

Serv. Soc. \& Saúde, Campinas, SP v.14, n.1(19), p. 57-90, jan./jun. 2015 ISSN 1676-6806
} 


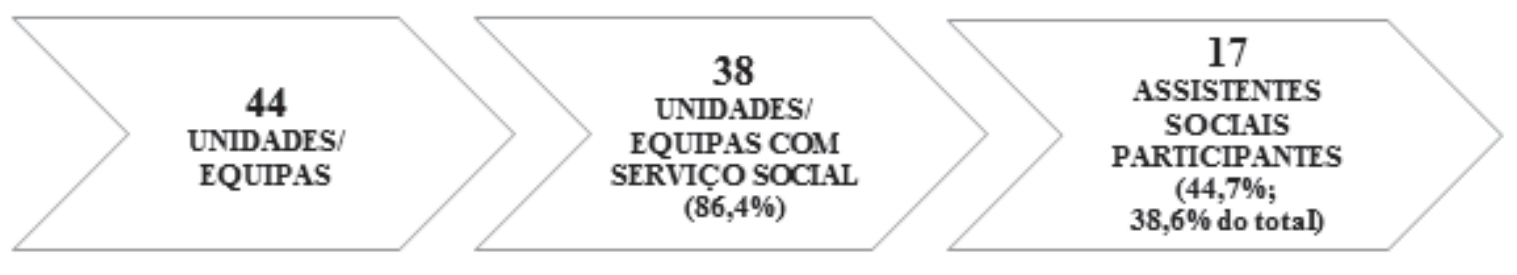

Figura 1. Fluxograma do processo de amostragem

Na Figura 1 pode-se observar-se que do processo de amostragem resultou uma amostra de 17 profissionais, o que corresponde a $38,6 \%$ do universo de unidades/equipas identificadas a nível nacional e a $44,7 \%$ das que integram profissionais de Serviço Social, ou seja, das elegíveis para o estudo. Na Figura 2 estão representadas as unidades/equipas que existem em todo o território nacional, com uma estrela assinalamos as que contam com a intervenção do Serviço Social ( $\mathrm{n}=38$ ), com um círculo sinalizamos as 6 unidades/equipas que não integram assistente social na equipa multiprofissional.

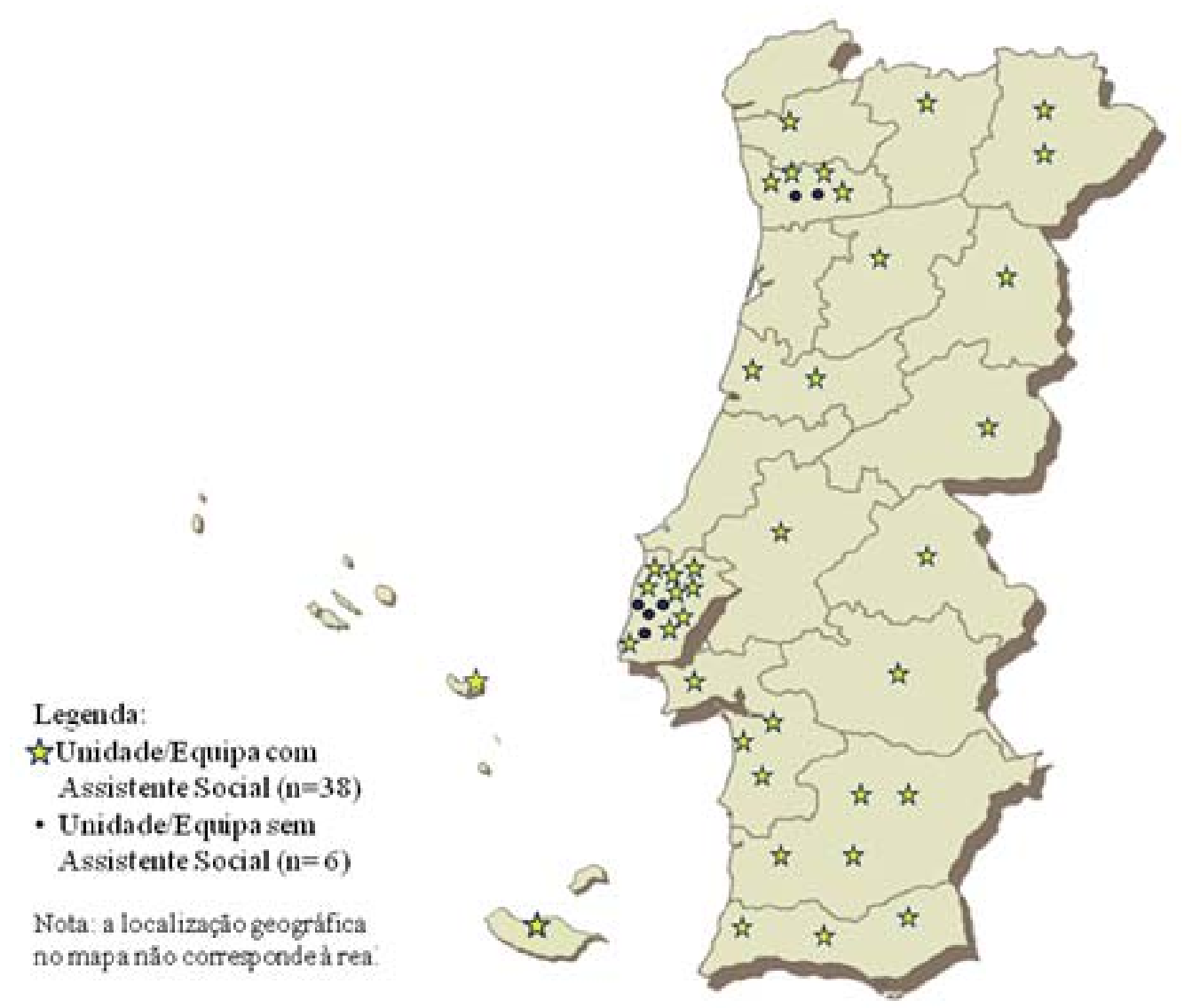

Figura 2. Distribuição das Unidades/Equipas pelos Distritos e Regiões Autónomas de Portugal 
Tabela 1. Caracterização da amostra

\begin{tabular}{|c|c|c|c|c|c|c|}
\hline Sexo & & $\mathrm{n}=17$ & & $\%(100)$ & & \\
\hline Feminino & & 16 & & 94,1 & & \\
\hline Masculino & & 1 & & 5,9 & & \\
\hline Idade & $\mathrm{M}$ & DP & $\mathrm{Me}$ & Mo & Mín & Máx \\
\hline$(\mathrm{n}=16)$ & 43,19 & 9,375 & 44 & 44 & 25 & 57 \\
\hline
\end{tabular}

n= número de casos; $\mathrm{M}=$ Média; $\mathrm{DP}=$ Desvio Padrão; $\mathrm{Me}=$ Mediana; $\mathrm{Mo=}$ = Moda; Mín=Mínimo; Máx= Máximo

$\mathrm{Na}$ tabela acima podemos constatar que os assistentes sociais que responderam ao inquérito são maioritariamente do sexo feminino $(94,1 \%)$, sendo apenas 1 do sexo masculino $(5,9 \%)$. Os profissionais que compõem a amostra têm, em média, uma idade de 43 anos ( $D P=9,375)$, variando entre os 25 e os 57 anos.

\section{INSTRUMENTOS, PROCEDIMENTOS E ANÁLISE DOS DADOS}

Foi realizado um levantamento prévio dos dados disponíveis informaticamente de todas as unidades existentes no território português, tendo sido efetuados contactos para uma breve caracterização. Identificado o universo de instituições com assistente social, foi remetido um pedido formal de colaboração no estudo, nalguns casos dirigido a comissões de ética, cumprindo as exigências de consentimento informado.

O estudo utilizou o inquérito por questionário como instrumento de recolha de dados, atendendo à dispersão territorial da amostra, tendo sido disponibilizado e preenchido online. Após a recolha de dados, entre janeiro de 2014 e maio de 2014, procedeu-se ao tratamento quantitativo para as respostas fechadas, através da utilização do software IBM SPSS Statistics 21, utilizando técnicas de estatística descritiva (frequências e medidas de tendência central). 


\section{RESULTADOS}

Ao observarmos a tabela 2, verificamos que o ano de licenciatura dos profissionais se situa entre 1978 e 2011, sendo licenciados há 3, no mínimo, e há 36, no máximo, sendo em média formados há 18,5 anos.

Tabela 2. Formação do assistente social

\begin{tabular}{|c|c|c|c|c|c|c|}
\hline \multirow[b]{2}{*}{ Pós-graduação } & & \multicolumn{2}{|l|}{$\mathrm{n}=17$} & \multicolumn{3}{|l|}{$\%(100)$} \\
\hline & & \multirow{2}{*}{\multicolumn{2}{|c|}{11}} & & & \\
\hline \multicolumn{2}{|l|}{ Tem } & & & \multicolumn{3}{|l|}{64,7} \\
\hline Não tem & & \multicolumn{2}{|l|}{6} & \multicolumn{3}{|l|}{35,3} \\
\hline \multicolumn{7}{|c|}{ Formação Específica em } \\
\hline \multicolumn{7}{|c|}{ Cuidados Paliativos } \\
\hline Tem & \multicolumn{3}{|c|}{14} & \multicolumn{3}{|l|}{82,4} \\
\hline \multirow{3}{*}{$\begin{array}{l}\quad \text { Não tem } \\
\text { Há quantos anos } \\
\text { estão licenciados } \\
(\mathrm{n}=16)\end{array}$} & \multicolumn{3}{|c|}{3} & \multicolumn{3}{|l|}{17,6} \\
\hline & M & DP & $\mathrm{Me}$ & Mo & Mín & Máx \\
\hline & 18,5 & 10,086 & 16,5 & 13 & 3 & 36 \\
\hline
\end{tabular}

$\mathrm{n}=$ número de casos; $\mathrm{M}$ = Média; $\mathrm{DP}=$ Desvio Padrão; $\mathrm{Me}=$ Mediana; $\mathrm{Mo}=$ Moda;

A maioria dos profissionais tem formação específica em cuidados paliativos $(82,4 \%)$ e detém formação pós-graduada (64,7\%). Dos que afirmaram ter uma pós-graduação, a grande maioria refere ser na área da saúde, apresentando também formação em intervenção social com população sénior e proteção de menores. Dos 17 participantes, 4 têm mestrado, 3 destes cumulativamente com uma pós-graduação. A formação de segundo ciclo foi obtida nas áreas do Serviço Social, família e sistemas sociais e mestrados na área da saúde. Não se registaram respostas de formação ao nível de doutoramento.

Tabela 3. Exercício Profissional

\begin{tabular}{|c|c|c|c|c|c|c|c|}
\hline & $\mathbf{M}$ & DP & Me & Mo & Mín & Máx & $\mathbf{n}$ \\
\hline $\begin{array}{l}\text { Há quantos anos trabalha como } \\
\text { assistente social }\end{array}$ & 17,82 & 9,964 & 17 & $12 *$ & 3 & 36 & 17 \\
\hline $\begin{array}{l}\text { Há quantos anos trabalha em } \\
\text { cuidados paliativos }\end{array}$ & 5,47 & 3,608 & 4 & 3 & 1 & 13 & 17 \\
\hline $\begin{array}{l}\text { Sempre trabalhou em cuidados } \\
\text { paliativos }\end{array}$ & & $\mathrm{n}$ & & & $\%$ & & \\
\hline $\begin{array}{ll}\text { Sim } & \text { Não }\end{array}$ & & $\begin{array}{c}4 \\
13\end{array}$ & & & $\begin{array}{l}23,5 \\
76,5\end{array}$ & & \\
\hline
\end{tabular}

n= número de casos; $\mathrm{M}$ = Média; $\mathrm{DP}=$ Desvio Padrão; $\mathrm{Me}=$ Mediana; Mo = Moda; Mín = Mínima; Máx = Máximo

Ao analisarmos os dados da tabela 3, podemos constatar que o tempo que os profissionais exercem a sua profissão como assistente sociais é muito maior do que o Serv. Soc. \& Saúde, Campinas, SP v. 14, n. 1 (19), p. 57-90, jan./jun. 2015 ISSN 1676-6806 
dedicado aos cuidados paliativos. Em relação à primeira variável a média é de 17,82 anos ( $\mathrm{DP}=9,964)$, e varia entre 3 e 36 anos. No que toca aos anos de trabalho na área, a amplitude é menor (de 1 a 13 anos), com uma média de 5,47 anos (DP =3,608). O número de inquiridos que sempre trabalhou na área dos cuidados paliativos $(23,5 \%)$ é muito menor do que aqueles que exerceram funções noutras áreas $(76,5 \%)$, tendo a grande maioria trabalhado sempre na área da saúde.

Pode verificar-se que em relação aos anos de existência das equipas há uma grande dispersão entre o mínimo e o máximo, ou seja, a primeira unidade foi fundada há 23 anos (máximo), tendo a última (mínimo) iniciado a sua atividade em 2014, no corrente ano, sendo que, em média, existem há 6,81 anos $(\mathrm{DP}=6,04)$.

Tabela 4. Caraterização e Evolução da Unidade/Equipa

\begin{tabular}{|c|c|c|c|c|c|c|c|}
\hline \multirow{2}{*}{$\begin{array}{l}\text { Anos de existência } \\
\qquad(\mathrm{n}=16)\end{array}$} & $\mathrm{M}$ & DP & $\mathrm{Me}$ & Mo & Min & Máx & $\mathrm{N}$ \\
\hline & 6,812 & 6,036 & 5 & 5 & 0 & 21 & 16 \\
\hline \multirow{3}{*}{$\begin{array}{l}\text { Natureza Jurídica } \\
\text { Pública } \\
\text { Instituição Particular de }\end{array}$} & \multicolumn{2}{|c|}{$\mathrm{n}=16$} & \multicolumn{5}{|c|}{$\%(100)$} \\
\hline & \multirow{2}{*}{\multicolumn{2}{|c|}{12}} & \multirow{2}{*}{\multicolumn{5}{|c|}{75,0}} \\
\hline & & & & & & & \\
\hline $\begin{array}{l}\text { Solidariedade Social } \\
\text { (IPSS) }\end{array}$ & \multicolumn{2}{|c|}{1} & \multicolumn{5}{|c|}{6,3} \\
\hline Privada & \multicolumn{2}{|c|}{3} & \multicolumn{5}{|c|}{18,8} \\
\hline $\begin{array}{l}\text { Unidade depende de outra } \\
\text { estrutura }\end{array}$ & \multicolumn{2}{|c|}{$\mathrm{n}=15$} & \multicolumn{5}{|c|}{$\%(100)$} \\
\hline Sim & \multicolumn{2}{|c|}{14} & \multicolumn{5}{|c|}{93,3} \\
\hline Não & \multicolumn{2}{|c|}{1} & \multicolumn{5}{|c|}{6,7} \\
\hline
\end{tabular}

n= número de casos; $\mathrm{M}=$ Média; DP= Desvio Padrão; $M e=$ Mediana; Mo= Moda; Min=Mínimo; Max= Máximo

Em relação à natureza jurídica da unidade/equipa, a maior parte são entidades públicas (75\%), apenas uma é IPSS (6,3\%) e 18,8\% são privadas.

Dos 17 inquiridos, 8 referem que a unidade mantém a mesma orgânica interna desde a sua criação, sendo que 5 evoluíram de unidades já existentes, como é o caso de serviços hospitalares e serviços de saúde de uma Misericórdia. Os restantes 4 são omissos em relação a esta informação. A evolução verificada nas 5 unidades referidas atrás foi justificada pela necessidade de adaptação às necessidades da população assistida.

Este facto correspondeu à intenção de se ajustar a organização do serviço ao trabalho efectivamente aí realizado [...]. Reconhece-se, assim, a importância crucial na evolução da medicina [...]" [inq.1] 
No caso de uma das unidades, que iniciou o seu funcionamento com a designação atual, fazem realçar que se registaram mudanças ao nível da organização e abrangência da prestação dos seus serviços.

Aquando a sua criação e durante os 2 primeiros anos, só apoiava um dos hospitais, somente a doentes em situação de internamento e para patologias do foro oncológico. Posteriormente e de forma gradual alargou-se aos outros hospitais que compõem o centro hospitalar, bem como a patologias crónicas [inq. 16].

Tabela 5. Constituição da equipa de trabalho

\begin{tabular}{|c|c|c|c|c|}
\hline \multirow{2}{*}{ Profissionais na equipa } & \multicolumn{2}{|c|}{ Existe na equipa } & \multicolumn{2}{|c|}{ Não existe na equipa } \\
\hline & $\mathrm{N}$ & $\%$ & $\mathrm{n}$ & $\%$ \\
\hline Médico & 17 & 100 & - & - \\
\hline Enfermeiro & 17 & 100 & - & - \\
\hline Assistente social & 17 & 100 & - & - \\
\hline Psicólogo & 15 & 88,2 & 2 & 11,8 \\
\hline Fisioterapeuta & 7 & 41,2 & 10 & 58,8 \\
\hline Terapeuta ocupacional & 7 & 41,2 & 10 & 58,8 \\
\hline $\begin{array}{l}\text { Auxiliares da ação } \\
\text { médica }\end{array}$ & 6 & 35,3 & 11 & 64,7 \\
\hline $\begin{array}{l}\text { medica } \\
\text { Terapeuta da fala }\end{array}$ & 5 & 29,4 & 12 & 70,6 \\
\hline Administrativo & 5 & 29,4 & 12 & 70,6 \\
\hline Capelão & 4 & 23,5 & 13 & 76,5 \\
\hline Assistente espiritual & 2 & 11,8 & 15 & 88,2 \\
\hline Nutricionista & 4 & 23,5 & 13 & 76,5 \\
\hline Dietista & 4 & 23,5 & 13 & 76,5 \\
\hline Voluntários & 3 & 17,6 & 14 & 82,4 \\
\hline Animador sociocultural & 3 & 17,6 & 14 & 82,4 \\
\hline Assistente operacional & 3 & 17,6 & 14 & 82,4 \\
\hline Farmacêutico & 2 & 11,8 & 15 & 88,2 \\
\hline Cabeleireiro & 1 & 5,9 & 16 & 94,1 \\
\hline
\end{tabular}

Na tabela 5 podemos constatar que na composição das equipas, em todas elas estão representados 3 grupos profissionais: médicos, enfermeiros e assistentes sociais. Nas restantes, a grande maioria conta, também, com a integração do psicólogo $(88,2 \%)$, da fisioterapia e do terapeuta ocupacional (ambos presentes em 41,2\% das equipas), sendo apontados, com uma percentagem menor os auxiliares da ação médica $(35,5 \%)$. Os restantes grupos profissionais, de diferentes categorias, encontram-se distribuídos de forma heterogénea pelas equipas. 
Tabela 6. Formação profissional da equipa

\begin{tabular}{lcc}
\hline Os profissionais têm formação em cuidados paliativos & $\mathrm{n}=17$ & $\%(100)$ \\
\cline { 2 - 3 } Sim, mas poucos & 3 & 17,6 \\
Sim, pelo menos metade & 5 & 29,4 \\
Sim, todos ou quase todos & 9 & 52,9 \\
Apoio da instituição na formação continuada em & $\mathrm{n}=16$ & $\%(100)$ \\
cuidados paliativos & 13 & 81,3 \\
$\quad$ Apoia & 3 & 18,8 \\
Não apoia & $\mathrm{n}=16$ & $\%(100)$ \\
Considera o apoio da instituição para a formação & 1 & 5,9 \\
Nada efetivo & 3 & 17,6 \\
Pouco efetivo & 10 & 58,8 \\
Efetivo & 2 & 11,8 \\
Muito efetivo & &
\end{tabular}

$\mathrm{Na}$ tabela 6, ressalta-se que os profissionais com formação em cuidados paliativos $(52,9 \%)$ ultrapassam os que não a têm. O mesmo se verifica no que respeita ao apoio prestado pela instituição à formação continuada nesta área, onde $81.3 \%$ apresentam resposta positiva, os inquiridos consideram, de igual forma, que o apoio da mesma na formação contínua é, na sua maioria, um apoio efetivo $(58,8 \%)$.

Tabela 7. Estabilidade da equipa

\begin{tabular}{lcc}
\hline Estabilidade na equipa & $\mathrm{n}=17$ & $\%(100)$ \\
\cline { 2 - 3 } Sim, tem existido ao longo do tempo & 12 & 70,6 \\
Não tem existido ao longo do tempo & 5 & 29,4 \\
\hline Nível de estabilidade percebido & $\mathrm{n}=16$ & $\%(100)$ \\
Instabilidade & 1 & 6,3 \\
Estabilidade moderada & 9 & 56,3 \\
Estabilidade & 4 & 25,0 \\
Muita estabilidade & 2 & 12,5 \\
\hline
\end{tabular}

Os inquiridos apontam, claramente, para a estabilidade da constituição nas equipas (70,6\%). Ao classificarem essa estabilidade, os inquiridos situam-na entre a "estabilidade moderada" (56,3) e a "estabilidade" (25\%), sendo residuais as classificações extremas.

Como podemos ver na tabela 8, o tempo de dedicação situa-se com maior peso no "adequado" (68,3\%), sendo que os demais aspetos, como sejam a relação contratual e a satisfação com a remuneração pendem para uma avaliação com carga mais negativa. Serv. Soc. \& Saúde, Campinas, SP v.14, n.1(19), p. 57-90, jan./jun. 2015 ISSN 1676-6806 
Ao nível do vínculo laboral, os contratos a termo incerto $(53,3 \%)$ são superiores aos a termo certo $(46,7 \%)$. A percentagem mais elevada na satisfação com a remuneração recebida encontra-se no "insatisfeito" (37,5\%), seguida do "moderadamente satisfeito" $(31,3 \%)$. É de destacar, também, que a maioria dos inquiridos classificou a carga de trabalho como "adequada" (50\%) ou "pouco adequada" (43,8\%).

Tabela 8. Condições de trabalho na unidade

\begin{tabular}{lcc}
\hline Tempo de dedicação & $\mathrm{n}=16$ & $\%(100)$ \\
Inadequado & 3 & 18,8 \\
Pouco adequado & 1 & 6,3 \\
Adequado & 11 & 68,3 \\
Muito adequado & 1 & 6,3 \\
Relação contratual & $\mathrm{n}=15$ & $\%(100)$ \\
Contrato a termo certo & 7 & 46,7 \\
Contrato a termo incerto & 8 & 53,3 \\
Satisfação com remuneração & $\mathrm{n}=16$ & $\%(100)$ \\
Muito insatisfeito & 1 & 6,3 \\
Insatisfeito & 6 & 37,5 \\
Moderadamente satisfeito & 5 & 31,3 \\
Satisfeito & 4 & 25,0 \\
Muito satisfeito & 0 & - \\
Adequação dos recursos humanos & $\mathrm{n}=17$ & $\%(100)$ \\
Muito inadequado & 0 & - \\
Inadequado & 0 & - \\
Pouco adequado & 5 & 29,4 \\
Adequado & 10 & 58,8 \\
Muito adequado & 2 & 11,8 \\
Carga de trabalho & $\mathrm{n}=16$ & 6,3 \\
Muito inadequada & 1 & - \\
Inadequada & 0 & 43,8 \\
Pouco adequada & 7 & 50,0 \\
Adequada & 8 & - \\
Muito adequada & 0 & \\
\hline
\end{tabular}

\section{DISCUSSÃO DOS RESULTADOS}

\section{Percurso formativo e profissional do(a) assistente social}

Dos 17 assistentes sociais inquiridos, a maioria optou por uma formação pósgraduada após a licenciatura, detendo também, na sua maior parte, uma especialização na formação em cuidados paliativos. A amostra, revela, assim, um nível de formação avançado e especializado. 
Estes cuidados, por serem complexos, enquadram como um dos princípios subjacentes à sua prática (filosofia) a efetividade, a eficiência e os cuidados de saúde baseados na evidência científica (SANTOS; CAPELAS, 2011), requerem uma formação de nível superior aos profissionais que desenvolvem a sua intervenção no âmbito destes cuidados (VANZINI, 2010), considerando-se necessário um conjunto de competências específicas com formação teórica e prática adequadas. A nível internacional, o Conselho da Europa (2003) e a EAPC (2009) explicitam a necessidade de formação nos cuidados paliativos em três níveis diferentes: básico, intermédio e avançado. Em Portugal, a circular normativa do Ministério da Saúde em 2004, primeira versão do PNCP, reconhece a necessidade de os profissionais possuírem formação específica para desempenharem as suas funções, ideia reforçada pelo Decreto-Lei que cria a Rede Nacional de Cuidados Continuados (em 2006). Posteriormente, a UMCCI (2010a) na estratégia para o desenvolvimento do PNCP volta a destacar que é necessária uma "formação específica adequada e sem esta, não é possível a prática deste tipo de cuidados" (ibid., p. 18).

No entanto, Marques et al. (2009) referem que no nosso país os cuidados paliativos ainda não são devidamente reconhecidos como área de competência ou especialização. Contudo, esta formação mostra algum desenvolvimento na viragem do milénio com o surgimento dos mestrados em cuidados paliativos no ensino universitário público e privado em Portugal, bem como da oferta de cursos de pós-graduação, o que resultou no aumento significativo dos trabalhos concluídos sendo a investigação nesta área relativamente recente (MARQUES et al., 2009; SANTOS; CAPELAS, 2011).

Apesar dos dados constatados no nosso estudo apontarem para a grande generalidade dos profissionais terem apostado na formação em cuidados paliativos e, embora não tenha sido uma variável por nós explorada, Christ e Sormanti (1999), no estudo que realizaram com 121 profissionais de Serviço Social que participaram na reunião anual da Association of Oncology Social Work, chegaram à conclusão que o desenvolvimento das competências no que respeita ao cuidado dos doentes terminais é assimétrico e não suficientemente integrado com conceitos teóricos e pesquisas acerca do mesmo, tendo os inquiridos revelado pouca formação acerca do tema. Bifulco e Iochida (2009), no estudo que realizaram com 15 profissionais de saúde, concluíram que a maioria dos entrevistados realçaram que esta formação é, na sua generalidade, uma formação predominantemente científica, não existindo estágios nestas formações. Na 
mesma linha constataram Fonseca e Geovanini (2013), que identificaram, através dos discursos dos participantes,

[...] uma presença minoritária de disciplinas referentes aos cuidados paliativos nos currículos de graduação. Como resultado é sugestiva a falta de preparação, tanto técnica como emocional, dos profissionais para lidarem com as questões limite de vida e morte no ambiente hospitalar (ibid., p. 124).

Grande parte dos profissionais declarou que não trabalhou sempre na área dos cuidados paliativos mas mantiveram-se no âmbito da área da saúde, área de inserção destes cuidados, apesar de existirem diferenças entre os campos de intervenção, um mais genérico e outro mais diferenciado, com processos de intervenção específicos. Em relação à experiência de trabalho dos profissionais, Bifulco e Iochida (2009) referem que a vivência obtida por meio da experiência em cuidados paliativos é muito importante para fazer com que estes profissionais entendam e lidem melhor com os doentes. Estes autores atribuem uma grande importância ao significado da experiência próxima da morte, aliada sempre à formação do profissional:

[...] é preciso que o profissional da saúde, além do conhecimento adquirido, desenvolva a sensibilidade necessária, colocando os fundamentos humanitários de sua formação e de sua trajetória pessoal como indispensáveis à percepção e à contenção do sofrimento que vivenciam os pacientes em sua terminalidade" (BIFULCO; IOCHIDA, 2009, p. 98).

Machado, Pessini e Hossne (2007) realçam, neste sentido, a necessidade urgente em se alterar os planos curriculares destes profissionais de saúde.

\section{Estrutura atual e trajetória da unidade/equipa}

No nosso estudo, a primeira unidade de cuidados paliativos foi criada há 23 anos, sendo que a última iniciou atividade já neste ano de 2014. Como se pode constatar, o desenvolvimento destes cuidados no nosso país é uma atividade recente e que continua em construção. Segundo Marques et al. (2009, p. 33), antes de 1992 não há qualquer referência a organizações estruturadas de cuidados paliativos no país. No nosso estudo a unidade mais antiga e, por isso, pressupõe-se que tenha sido a primeira unidade, foi fundada em 1992 com 20 camas de internamento para doentes com doença oncológica avançada, avança-se, também, que a maioria das unidades/equipas foi criada nos últimos 5 anos (10 de um total de 16 respostas). Ainda segundo o autor acima citado é necessário realçar que a introdução dos cuidados paliativos não se ficou a dever Serv. Soc. \& Saúde, Campinas, SP v. 14, n. 1 (19), p. 56-90, jan./jun. 2015 ISSN 1676-6806 
[...] a uma iniciativa governamental estruturada mas sim ao interesse de alguns pioneiros pelo tratamento da dor crónica dos doentes com doença oncológica avançada e ainda pela necessidade de ser garantida a continuidade dos cuidados dos doentes nas fases mais avançadas das doenças incuráveis e irreversíveis (MARQUES et al., 2009, p. 33).

Estes dados levam-nos a supor uma falta de interesse na aposta nesta área de especialização, uma vez que o início da institucionalização destes cuidados não foi feita por parte de entidades estatais e a continuidade do desenvolvimento e expansão continuam muito aquém das necessidades da população. Ainda segundo os últimos autores a razão que tem dificultado o desenvolvimento dos cuidados paliativos prendese com a "frouxidão da prática política-tendo em conta a hegemonia do serviço nacional de saúde" (MARQUES et al., 2009, p. 38).

A resposta às necessidades destes doentes passa pela criação de uma rede alargada de serviços, rede esta que deve ir desde os cuidados no domicílio aos cuidados em unidades de internamento específicas e em hospitais de agudos, passando pelas instituições de cuidados de longa duração. Olhando para trás no tempo, constatam, ainda assim, que os

[...] últimos 15 anos trouxeram consciência da importância desta área, o surgimento de equipas, fruto sobretudo do entusiasmo e persistência de grupos de profissionais que, em condições de dureza, souberam persistir no seu objetivo maior de dar dignidade e qualidade de vida aos que não se curam (MARQUES et al., 2009, p. 38).

Efetivamente, dos inquiridos que nos apontaram mudanças efetuadas ao longo dos tempos justificaram-nas como necessidade de organização e extensão dos cuidados para se adaptarem às necessidades da população.

Apesar de tudo o que foi alcançado, particularmente nas últimas duas décadas Neto (2010) afirma que ainda há muito a oferecer para que estes doentes tenham dignidade, conforto e qualidade de vida.

\section{Equipa multiprofissional e condições de trabalho}

No corrente estudo foram identificadas 44 unidades/equipas a nível nacional, sendo que destas 38 contavam com a presença do assistente social na equipa de trabalho, destes 17 aceitaram participar na investigação. Na constituição das equipas o médico, o enfermeiro e o assistente social foram os três profissionais identificados como a constituição básica das equipas caracterizadas, acrescentando-se, na maioria das 
vezes, o psicólogo, o fisioterapeuta, o terapeuta ocupacional e os auxiliares da ação médica. Verifica-se nalguns casos, uma constituição bastante alargada e variada nas categorias profissionais representadas, e noutros casos uma constituição mais restrita. Chama-se a atenção para o facto de poder haver eventualmente outros profissionais não elencados pelo inquirido, atendendo a que a pergunta foi aberta e alguns podem ter optado por identificar todos os profissionais e outros apenas parte da equipa.

Segundo Payne (2012), a "diversidade de competências profissionais envolvida nos cuidados paliativos tem vindo a expandir-se desde a década de 60 do século XX" (ibid., p. 118). Na LBCP não são especificados, em concreto, os profissionais que devem fazer parte da equipa apenas referem que a prestação de cuidados nas unidades e equipas de cuidados paliativos são "asseguradas por equipas multidisciplinares com dotações adequadas à garantia de uma prestação de cuidados de qualidade [...]". A ANCP (2006) e a UMCCI (2010a) consideram que estas equipas devem ter como elementos básicos o médico, o enfermeiro e o assistente social, indo ao encontro da constituição mais frequente da equipa técnica no universo do nosso estudo. No entanto, no despacho n. 10429 de agosto de 2014, já publicado no terminus do estudo, determina na alínea 2 que a constituição das equipas intra-hospitalares de suporte em cuidados paliativos deve ter no mínimo a presença do médico, do enfermeiro e do psicólogo, colocando de parte a intervenção dos assistentes sociais, o que parece ir à revelia das orientações das instâncias internacionais, tendo a Associação dos Profissionais de Serviço Social manifestado junto do Ministério da Saúde português a sua reivindicação de revisão do enunciado no referido diploma.

Esta nova equipa básica proposta pelo diploma não parece ir ao encontro da realidade das equipas existentes, sendo que as equipas existentes tendencialmente encaram como equipa básica quatro categorias profissionais: médico(a), enfermeiro(a), assistente social e psicólogo(a).

Para Payne (2012), o pessoal médico e de enfermagem estão no centro de qualquer prestação deste tipo de cuidados, "uma vez que a gestão da dor e dos sintomas são elementos fundamentais de um serviço holístico destinado a sintomas cada vez mais complexos e difíceis de gerir, e que constituem o ponto de partida do próprio serviço" (ibid., p. 118). No entanto, o Serviço Social na equipa multidisciplinar revela-se fundamental, uma vez que para muitos doentes, a ajuda no fim de vida pode dispensar a assistência médica e de enfermagem (PAYNE, 2012; REITH; PAYNE, 2009). No Serv. Soc. \& Saúde, Campinas, SP v. 14, n. 1 (19), p. 57-90, jan./jun. 2015 ISSN 1676-6806 
entanto, outros profissionais são igualmente importantes nos cuidados a prestar, por isso, a ANCP (2006) considera que "são desejáveis outros contributos, equacionados sempre em função das necessidades do binómio doente-família” (ibid., p. 3).

Efetivamente é consensual entre organismos internacionais e nacionais de referência nesta área que os cuidados paliativos são exemplo de uma atividade complexa e, por isso, necessitam de uma intervenção assente numa abordagem interdisciplinar, pois no atendimento ao doente paliativo é necessária uma atenção integral e holística pela multiplicidade de dimensões a que atendem (BARBERO; DÍAZ, 2007, NETO, 2010; OMS, 2002, TWYCROSS, 2003, VANZINI, 2010).

A UMCCI (2010) realça que a prestação destes cuidados numa unidade/equipa de cuidados paliativos pressupõe um conjunto de profissionais devidamente treinados para a definição do tipo de doentes que irão atender (fase da doença, patologias, níveis de complexidade). Ao nível da formação dos elementos das equipas que fazem parte do nosso estudo pelo menos metade a quase todos ou até mesmo todos os profissionais detêm de formação em cuidados paliativos, onde a própria instituição apoia a formação continuada na área, tendo os profissionais respondentes considerado este apoio entre um "apoio pouco efetivo e efetivo".

Apesar de cada profissional pertencer a uma determinada categoria, dificilmente se pode fazer um trabalho interdisciplinar sem uma formação multidisciplinar, independentemente da formação específica de cada um. Os cuidados paliativos têm um marco conceptual e metodológico que tem de ser também transdisciplinar. O profissional de Serviço Social deverá conhecer, por exemplo, o esquema global da escala de dor ou escala analgésica da OMS (BARBERO; DÍAZ, 2007; LÓPEZ, NERVI; TABOADA, 2005). Em algumas questões a formação tem de ser comum e partilhada, para falarem a mesma linguagem e não surgirem obstáculos na comunicação.

Os resultados do estudo de Torres-Mesa, Schmidt-Riovalle e García-García, (2013, p. 464) mostram que apenas metade do pessoal que trabalha com os pacientes que se confrontam com um prognóstico de vida limitado, crê que tem a formação adequada para cuidar deles. O mesmo constatou Christ e Sormanti (1999), tendo os assistentes sociais da amostra do seu estudo revelado não se sentirem preparados para este trabalho, quer pela insuficiência da formação, quer pelo facto de não se encontrarem suportados por programas de formação continuada com temas específicos de cuidados paliativos. Segundo dados da UMCCI foram realizadas pela mesma, entre Serv. Soc. \& Saúde, Campinas, SP v.14, n.1(19), p. 57-90, jan./jun. 2015 ISSN 1676-6806 
2006 e 2010, 21 ações de formação em contexto laboral, que englobaram 542 participantes, sendo que "apesar dos esforços de formação encetados, verificam-se ainda carências de formação em Cuidados Paliativos" (UMCCI, 2010a, p. 23). Ainda segundo esta investigação realizada em 2009, 36\% dos médicos, $18 \%$ dos enfermeiros e $45 \%$ dos assistentes sociais declararam não ter formação em cuidados paliativos.

Segundo a RNCCI (2013), desde 2007, 2012 foi o ano em que houve menos ações de formação e que abrangeram menos formandos. O relatório aponta o atual contexto financeiro e as limitações nos recursos humanos como uma das causas da quebra das formações disponibilizadas aos seus funcionários.

As condições de trabalho, entendidas como o tempo que os profissionais dedicam à profissão, a sua relação contratual, a satisfação com a remuneração recebida, a adequação dos recursos humanos, a carga de trabalho e a estabilidade da própria equipa, não esquecendo que na nossa amostra existem mais profissionais a trabalharem com contratos a termo incerto do que a termo certo, espelham as atuais condições em que se encontram os profissionais. As respostas não são totalmente negativas, mas também não se obtiveram resultados plenamente satisfatórios por parte dos inquiridos, ou seja, de uma forma geral os profissionais consideram estas condições "pouco adequadas, moderadamente adequadas ou adequadas". Alguns dos inquiridos referem que a falta de pessoal e os que trabalham terem um horário parcial, bem como o facto de um profissional estar dividido por vários serviços faz com que a carga de trabalho aumente levando muitas das vezes a ultrapassarem o horário legalmente instituído. Os profissionais constituintes da amostra do nosso estudo realçam, por isso, a necessidade de leis laborais adequadas.

De acordo com Rebelo (2012),

[...] a vivência da atual crise financeira internacional e de um ambiente económico especulativo novo, sujeito ao desconcerto que presentemente afeta os mercados financeiros, vêm deixando sequelas sociais. Na maioria dos países europeus - ante as perspectivas de um novo abrandamento do crescimento económico induzido por políticas orçamentais restritivas estima-se uma deterioração da conjuntura geral do emprego, em especial nos níveis de emprego [...] (ibid., p. 33).

Varela (2012) aborda também o surgimento do conjunto de medidas de carácter neoliberal a par da política de controlo orçamental, especificamente no campo do emprego, onde ocorreram alterações ao nível das relações contratuais de trabalho 
(possibilidade de despedimentos sem justa causa, aumento da carga horária de trabalho, redução dos salários, precariedade nas relações contratuais, entre outras).

Nesta perspectiva, Almeida (2012) realça um estudo do OPBPL no qual se analisou o estado das relações laborais em Portugal, tendo concluído que em 2012, 47,5\% dos trabalhadores portugueses classificam como "negativo" o estado das relações laborais em Portugal contra os 17,4\% que consideram como "positivo" e os 30,4\% como "neutro".

No campo da saúde, Côrtes e Carapinheiro (2013, p. 95) referem que o que tem acontecido é que a área da saúde, especificamente o SNS, tem-se confrontado "com linhas de força reformista que conferem à tendência de privatização" e as implicações destas reformas

[...] mostram como o SNS, as suas unidades de saúde e os seus profissionais têm estado sob o efeito da pressão de múltiplos interesses protagonizadas pela diversidade de atores que têm vindo a assumir posições estratégicas na condução das políticas de saúde para o reforço das tendências de racionalizações das despesas públicas em saúde, da privatização dos seus serviços de saúde e da mercadorização das atividades dos seus profissionais [...] (ibid., p. 95).

Em relação ao Serviço Social, Raichelis (2013, p. 624-625) afirma que o(a)s assistentes sociais têm vindo a ser afetados pelo excesso de formulários a preencher e folhas de cálculo padronizadas no computador; multiplicação de visitas domiciliárias para fins de fiscalização e controlo institucional das provisões e prestações sociais; preferência por um trabalho feito de forma burocrática e repetitiva, colocando de parte a reflexão crítica sobre a realidade dos utentes e seus territórios; insegurança do emprego, dominado pela precariedade e flexibilidade nos contratos, com redução ou até mesmo ausência de benefícios e direitos; intensificação do trabalho e das formas de controlo, baixos rendimentos, pressão pela produtividade e cumprimento de objetivos e resultados imediatos, falta de perspectivas de progressão e ascensão na carreira, entre outros. Apesar da autora se reportar à realidade brasileira, ela adequa-se em muito ao contexto das atuais condições de trabalho em Portugal, o que espelha, em parte, as percepções dos nossos inquiridos. 


\section{CONCLUSÕES}

O contexto de intervenção do Serviço Social tem sido alvo de severas transformações que têm limitado a concretização plena da sua ação. A área dos cuidados paliativos tem vindo, de igual forma, a ser afetada pelas sucessivas e agravadas medidas de austeridade assumidas nos últimos anos pelas opções políticas para lidar com a crise financeira, económica e social que, particularmente, Portugal e outros países da União Europeia vivem.

Apesar do já alcançado, por ser uma área recente dos cuidados de saúde, e por encontrar-se em fase de expansão, há ainda um longo caminho a percorrer para que o almejado em cobertura e em qualidade se espelhe na realidade. Os assistentes sociais intervêm na grande maioria das unidades/equipas existentes, constatando-se que hoje estes profissionais que prestam cuidados a estes doentes estão munidos de um grau de especialização superior ao passado (apesar de recente), aliás, os dados constatam que "pelo menos metade" ou "todos ou quase todos" têm formação específica em cuidados paliativos, no entanto, torna-se necessária uma maior aposta em toda a exigência educativa que envolve estes cuidados, sendo que neste âmbito não bastam apenas os conhecimentos teóricos, mas também contextos formativos práticos com contacto direto com os serviços e com os doentes. Não basta saber; é preciso "saber estar com" até ao fim.

A oferta pública é que assegura uma maior cobertura nacional em Portugal. No caminho percorrido pelas unidades/equipas desde a sua criação reconhecem a necessidade de um esforço contínuo para que os cuidados paliativos sejam quotidianamente levados à prática e reconhecida a sua premência a nível organizacional. Contudo, no interior destas unidades/equipas a estabilidade da constituição das equipas, apesar de percecionada pela amostra como sendo moderada, em relação às condições laborais a satisfação não é percebido um nível tão positivo, especialmente no que toca à relação contratual (maior número de vínculos a termo incerto), à (in)satisfação com a remuneração e à carga de trabalho apontada como sendo entre adequada e pouco adequada.

Gostaríamos, assim, de concluir evidenciando a importância da inserção dos assistentes sociais nos cuidados paliativos, pelo papel de destaque que assume na humanização, na organização das respostas às necessidades psicossociais, na articulação com as redes de suporte e comunitárias, no apoio ao ajustamento às mudanças sociais, familiares e pessoais do doente. No entanto, quer as suas funções Serv. Soc. \& Saúde, Campinas, SP v. 14, n. 1 (19), p. 57-90, jan./jun. 2015 ISSN 1676-6806 
quer as condições laborais ainda não estão devidamente regulamentadas, o que deixa uma franca margem para a possibilidade de desregulação e de desvalorização da sua ação. É cada vez mais pertinente uma reflexão e sustentação das práticas profissionais dos assistentes sociais nos cuidados paliativos no nosso país orientadas pelos valores da profissão, para o bem-estar das populações e para a concretização dos direitos dos cidadãos.

Recebido em 05.06.2015 - Aprovado em 09.06.2015

\section{REFERÊNCIAS}

ALMEIDA, P. P. Boas práticas laborais nas empresas. Dirigir: A revista para chefias e quadros, 117, 37-40. 2012. Acedido junho 7, 2014, em https://www.iefp.pt/documents/10181/702845/DIRIGIR_117.pdf/22b564b8-d3b7-41a3-96c7cd3de249f258.

ANCP. ACADEMIA NACIONAL DE CUIDADOS PALIATIVOS. Manual de Cuidados Paliativos. Rio de Janeiro: Diagraphic. 2009. Acedido outubro, 9, 2013, em http://www.nhu.ufms.br/Bioetica/Textos/Morte\%20e\%20o\%20Morrer/MANUAL\%20 DE\% 20CUIDADOS\%20PALIATIVOS.pdf.

ANCP. ASSOCIAÇÃO NACIONAL DE CUIDADOS PALIATIVOS. Organização de Serviços em Cuidados Paliativos. Recomendações da ANCP. 2006. Acedido outubro, 9, 2013, em http://www.apcp.com.pt/uploads/Recomendacoes_Organizacao_de_Servicos.pdf. ARAÚJO, M. M. T. \& SILVA, M. J. P. Estratégias de comunicação utilizadas por profissionais de saúde na atenção a pacientes sob cuidados paliativos. Ver. Esc. Enferm. USP, 46 (3), 626-632. 2012. Acedido dezembro, 11, 2013, em http://www.scielo.br/ pdf/reeusp/v46n3/14.pdf.

AStudillo, W., MENDinUETTA, C., CASADO, A. Cómo afrontar mejor las perdidas en cuidados paliativos. Rev. Soc. Esp. Dolor, 14 (7), 511-526. 2007. Acedido dezembro, 5, 2013, em http://scielo.isciii.es/pdf/dolor/v14n7/revision2.pdf. BARBERO, J. \& DÍAZ, L. Diez cuestiones inquietantes en cuidados paliativos. Anales Sis San Navarra, 30 (3), 71-86. 2007. Acedido dezembro, 11, 2013, em http:// scielo.isciii.es/scielo.php?pid=S1137-66272007000600006\&script=sci_arttext. Serv. Soc. \& Saúde, Campinas, SP v.14, n.1(19), p. 57-90, jan./jun. 2015 ISSN 1676-6806 
BIFULCO, V. A., IOCHIDA, L. C. A formação na graduação dos profissionais de saúde e a educação para os cuidados de pacientes fora de recursos terapêuticos de cura. Revista Brasileira de Educação Médica, 33 (1), 92-100. 2009. Acedido dezembro, 3, $2013 \mathrm{em} \mathrm{http://www.scielo.br/pdf/rbem/v33n1/13.pdf.}$

BRAGA, F. C., QUEIROZ, E. Cuidados paliativos: o desafio das equipes de saúde. Psicologia USP. N $N^{\circ} 23$ (3). pp. 413-429. 2013. Disponível em: http://www.scielo.br/scielo.php?script=sci_arttext\&pid=S0103$65642013000300004 \& \operatorname{lng}=$ en\&tlng=pt. 10.1590/S0103-65642013000300004.

BRANCO, F. A Profissão de Assistente Social em Portugal. Locus Soci@l, 3, 61-89. 2009.

CABRAL, M. V. (Coord.), SILVA, P.A., MENDES; H. Saúde e Doença em Portugal. Coimbra: Centro de Estudos Sociais. 2002.

CHRIST, G.H., SORMANTI, M. Advancing social work practice in end-of-life care.

Soc Work Health Care, 30 (2), 81-99. 1999. Acedido maio, 15, 2014, em http://www.ncbi.nlm.nih.gov/pubmed/10839248.

COMBINATO, D. S., QUEIROZ, M. S. Um estudo sobre a morte: uma análise a partir do método explicativo de Vigotski. Ciências \& Saúde Coletiva, 16 (9), 3893-3900. 2011. Acedido dezembro, 7, 2013, em http://www.scielo.br/pdf/csc/v16n9/a25v16n9.pdf.

CÔRTES, S., CARAPINHEIRO, G. Reformas de Sistemas de Saúde em Contextos de Reformas do Estado: Os Casos de Brasil e Portugal. Em Alves, F. Saúde, Medicina e Sociedade: Uma Visão Sociológica (pp. 75-98). Lisboa: Pactor. 2013.

CULLEN, A., CHADDOCK, B., HEARN, F. (2013). What's special about palliative care social work. Association of Palliative Care Social Workers. Acedido julho, 7, 2014 em http://www.ehospice.com/uk/ArticleView/tabid/10697/ArticleId/4838/language/enGB/View.aspx.

EAPC. European Association for Palliative Care. White Paper on standards and norms for hospice and palliative care in Europe. European - parte 1: Recommendations from the European Association for Palliative Care. European Journal of Palliative Care, 16 2009 Acedido abril, 9 , 2013 em http://www.eapcnet.eu/LinkClick.aspx?fileticket=f63pXXzVNEY\%3D\&tabid=735. 
EUROSTAT. European Commission. European Social Statistics. Acedido outubro, 4, 2013, em http://epp.eurostat.ec.europa.eu/cache/ITY_OFFPUB/KS-FP-13-001/EN/KSFP-13-001-EN.PDF.

FLORIANI, C. A., SCHRAMM, F. R. Cuidados paliativos: interfaces, conflitos e necessidades. Ciência \& Saúde Coletiva, 13 (2), 2123-2132. 2008. Acedido Dezembro, 7 2013, em http://www.scielosp.org/pdf/csc/v13s2/v13s2a17.pdf.

FLORIANI, C. A., SCHRAMM, F. R. Casas para os que morrem: a história do desenvolvimento dos hospices modernos. História, Ciências, Saúde, 17 (1), 165-180. 2010. Acedido dezembro, 11, 2013, em http://www.scielo.br/pdf/hcsm/v17s1/10.pdf. FONSECA, A., GEOVANINI, F. Cuidados Paliativos na Formação do Profissional da Área da Saúde. Brasileira de Educação Médica, 37 (1), 120-125. 2013. Acedido dezembro, 11, 2013, em http://www.scielo.br/pdf/rbem/v37n1/17.pdf. GUADALUPE, S. A intervenção do Serviço Social na Saúde com Famílias e em Redes de Suporte Social. In. CARVALHO, M. I. (Coord.). Serviço Social na Saúde. Lisboa: Pactor. 2012.

HOLlOWAY, M., TAPLIN, S. Death and social work-21st Century Challenges. The British Journal of Social Work, 43 (2), 203-215. 2013.

KOVACS, M. J. (2004). Comunicação nos programas de cuidados paliativos: uma abordagem multidisciplinar. In: PESSINI, L., BERTACHINI, L. Humanização e Cuidados Paliativos (258-289). EDUNISC-Edições Loyola. 2004. LÓPEZ, R.; NERVI, F.; TABOADA, P. Manual de Medicina Paliativa. Santiago: Pontificia Universidad Católica de Chile, Facultad de Medicina. 2005. Acedido outubro, 7, 2013, em http://cuidadospaliativos.org/archives/medicinafinal.pdf. LOYD, M. Dying and bereavement, spirituality and social work in a market economy of welfare. The British Journal of Social Work, 27 (2), 175-190. 1997.

LUZ, L. P. da, GOULART, P. M., BENINCÁ, S. O Grupo de apoio como estratégia metodológica para trabalhar o luto. Revista de Iniciação Científica, 5 (1), 1-10. 2007. Acedido julho, 12, 2014, em http://periodicos.unesc.net/index.php/iniciacaocientifica/article/view/171/175.

MACHADO, K. D. G.; PESSINI, L.; HOSSNE, W. S. A formação em cuidados paliativos da equipe que atua em unidade de terapia intensive: um olhar da bioética. Bioethikos. Centro Universitário São Camilo, 1 (1), 34-42. 2007. Acedido dezembro, 7, 2013, em http://www.saocamilo-sp.br/pdf/bioethikos/54/A_cuidados_paliativos.pdf. 
MARQUES, L., GONÇALVES, E., SAlAZAR, H., NETO, I.G., CAPELAS, M.L., TAVARES, M., SAPETA, P. O desenvolvimento dos cuidados paliativos em Portugal. Revista Patient Care. 14 (152), 32-38. 2009. Acedido outubro, 10, 2013, em http://www.apcp.com.pt/uploads/cp.pdf.

MARRERO, P., PEREIRA, S. A Valence Issue or a Transformation Definition: Is palliative care no more, no less than high-quality care? European Intersectorial and Multidisciplinary Palliative Care Research Training (Euro Impact), 1-11. 2013.

MARTINS, A. A Medicina paliativa como medicina de proximidade. Suspensão dos julgamentos gerais e acção médica em regime de familiaridade. Tese de Doutoramento, Universidade Nova de Lisboa. 2010.

MARTINS, A. C., ROMÃO, C. J. Profissões na saúde e desafios do trabalho de proximidade: médicos e assistentes sociais nos cuidados paliativos. III Seminário de I\&DT, organizado pelo C3i. Centro Interdisciplinar de Investigação e Inovação do Instituto Politécnico de Portalegre. 2012.

MATIAS, M. A. (2003). Jovens com Osteosarcoma e suas Famílias: elementos para uma análise da intervenção do Serviço Social. Intervenção Social: Saúde e Intervenção Social, 28, 57-78. 2003.

MENEZES, R. A. Tecnologia e "Morte Natural": o Morrer na Contemporaneidade. Physis: Revista Saúde Coletiva, 13 (2), 129-147. 2003. Acedido Dezembro, 10, 2013, em http://www.scielo.br/pdf/physis/v13n2/a08v13n2.pdf.

MOREIRA, I. M. P. B. O doente terminal em contexto familiar - Uma Análise da Experiência de Cuidar Vivenciada pela Família. Formasau. 2001.

NETO, I. G. (2006). Princípios e filosofia dos cuidados paliativos. Em BARBOSA, A. e NETO, I.G. (Ed.) Manual de Cuidados Paliativos, 17-52 Núcleo de Cuidados Paliativos, Centro de Bioética Faculdade de Medicina de Lisboa. 2006.

NETO, I. G. Cuidados Paliativos: Testemunhos. Lisboa: Aletheia. 2010.

NETO, I. G. Morrer é só o corolário de uma Medicina que entronizou a cura. Hospitalidade: Escutar \& Auscultar, 73 (284), 31-35. 2009.

OLAIZOLA, P. R. Qué lugar ocupa el trabajador social en el área de Cuidados Paliativos? Trabalho Final de Graduação, Universidad Nacional de Lujan. 2006.

OMS/WHO. World Health Organization. WHO Definition of Palliative Care. World Health Organization (WHO). Web site. 2009. Acedido outubro, 8, 2013, em http://www.who.int/cancer/palliative/definition/en/print.html. 
PALACIO, E. C., DIEGO, B. C., IGLESIAS, M. E., PINO, C. P., BERNARDINO, R. L. V., NAVARRO, I. M-S., ESCUDERO, M. P. Los cuidados Paliativos: una mirada desde el trabajo social. Trabajo Social Hoy, 54, 125-142. 2008. Acedido junho, 20, 2014, em http://dialnet.unirioja.es/servlet/ejemplar?codigo=207276.

PAYNE, M. Know your colleagues: Role of Social Work in end-of-life care. End of Life Care, 1 (1), 69-73. 2007. Acedido dezembro, 16, 2013, em http://endoflifecare.co.uk/journal/0101_colleagues.pdf.

PAYNE, M. Serviço Social em Cuidados Paliativos e em Fim de Vida. Em Carvalho, M. I. (coord.). Serviço Social na Saúde. Lisboa: Pactor. 2012.

PEREIRA, S. Burnout em cuidados paliativos. Uma perspectiva bioética. Tese de Doutoramento, doutoramento em Bioética, Instituto de Bioética - Universidade Católica Portuguesa. 2011.

PORTUGAL, S. Dádiva, Família e Redes Sociais. In: PORTUGAL, S., HENRIQUE, P. M. (org.), Cidadania, Políticas Públicas e Redes Sociais (39-54). Coimbra: Imprensa Universidade Coimbra. 2011.

RAICHELIS, R. Proteção Social e trabalho do assistente Social: tendências e disputas na conjuntura de crise mundial. Serviço Social \& Sociedade, 116, 609-635. 2013. Acedido outubro, 9, 2013, em http://www.scielo.br/pdf/sssoc/n116/03.pdf.

RAMOS, A. Medicina Paliativa/ Cuidados Continuados/ Unidade Multidisciplinar de Dor: Que realidade? Jornadas 30 anos de SNS - A experiência da Unidade de Saúde Lisboa Norte, Lisboa. Fev. 2009.

REBELO, G. Emprego Sénior e condições de trabalho. Dirigir: A revista para chefias e quadros, 117, 32-35. 2012. Acedido junho, 7, 2014, em https://www.iefp.pt/documents/10181/702845/DIRIGIR_117.pdf/22b564b8d3b7-41a3-96c7-cd3de249f258.

REITH, M., PAYNE, M. Social Work in end-of-life and palliative care. Policy Press. 2009.

RNCCI. Rede Nacional de Cuidados Continuados Integrados. (2013). Implementação e Monitorização da Rede Nacional de Cuidados Continuados Integrados. Relatório Final. 2013. Acedido junho, 5, 2014, em http://www4.segsocial.pt/documents/10152/3735071/Rel_Imple_Monit_RNCCI_2013. 
SANTOS, M. E., CAPELAS, M. E. Investigação em Cuidados Paliativos em Portugal. Cadernos de Saúde 4 (1), 63-69. 2011. Acedido maio, 15, 2014, em http://repositorio.ucp.pt/bitstream/10400.14/12508/1/CSaude_4-1\%20\%285\%29.pdf. SCHROEPFER, T. A., NOH, H. (2010). Terminally Ill Anticipation of Support in Dying and in Death. Journal of Social Work in End-of-Life \& Palliative Care, 6 (1), 73-90.

SIMÃO, A. B. et al. A atuação do Serviço Social junto a pacientes terminais: breves considerações. Serviço Social \& Sociedade, 102, 352-364. 2010. Acedido outubro, 16, 2013, em http://www.scielo.br/pdf/sssoc/n102/a09n102.pdf.

TORRES-MESA, L. M., SCHMIDT-RIOVALLE, J.; \& GARCÍA-GARCÍA, I. (2013). Conocimiento de la ley y preparación del personal sanitário sobre el processo asistencial de la muerte. Revista Escola Enfermagem USP, 47 (2) 464-470. Acedido dezembro, 11, 2013, em http://www.scielo.br/pdf/reeusp/v47n2/27.pdf.

TWYCROSS, R. Cuidados Paliativos. Lisboa Climepsi Editores. 2003.

UMCCI. Unidade de Missão para os Cuidados Continuados Integrados. Modelo de Referenciação de Utentes. 2009. Acedido julho, 9, 2014, em http://www.umcci.minsaude.pt/SiteCollectionDocuments/ModelodeReferenciacaoRNCCI_Setembro2009_co rrigido.pdf.

UMCCI. Unidade de Missão para os Cuidados Continuados Integrados. Estratégia para o Desenvolvimento do Programa Nacional de Cuidados Paliativos. Rede Nacional de Cuidados Continuados Integrados. 2010a. Acedido outubro, 3, 2013, em http://www.rncci.min-saude.pt/SiteCollectionDocuments/cuidadospaliativos_1-12011.pdf.

UMCCI, Unidade de Missão para os Cuidados Continuados Integrados. Resumo de actividades realizadas pela UMCCI na área dos Cuidados Paliativos. 2010b.

Acedido novembro, 7, 2013, em http://www.rncci.min-

saude.pt/SiteCollectionDocuments/resumo_actividades_UMCCI_Cuidados_Paliativos.p df.

VANZINI, L. El trabajo social en el ámbito de los cuidados paliativos: una profundización sobre el rol profesional. Revista de Trabajo Social y Acción Social, 47, 2173-8246. 2010. Acedido Dezembro, 11, 2013, em dialnet.unirioja.es/descarga/articulo/3655799.pdf. 
VARELA, R. (Coord.). Quem paga o Estado Social em Portugal. Lisboa: Bertrand Editora. 2012.

\section{DOCUMENTOS ÉTICO-JURÍDICOS}

PORTUGAL. Ministério da Saúde. Circular Normativa No 14/DGCG de 13/07/04.

PORTUGAL. Ministério da Saúde. Portaria n. ${ }^{\mathbf{1} 142-B / 2012}$ de 15 de maio de 2012. Diário da República n. ${ }^{\circ} 94$ - 1. a série. PORTUGAL. Lei 52/2012 de 5 de setembro de 2012. Diário da República n. ${ }^{\circ} 172.1^{\text {a }}$ série. $^{2}$ 
Serv. Soc. \& Saúde, Campinas, SP v. 14, n. 1 (19), p. 57-90, jan./jun. 2015 ISSN 1676-6806 